\title{
Recrystallization of a Cold Rolled Trip-assisted Steel during Reheating for Intercritical Annealling
}

\author{
Roumen PETROV, Leo KESTENS and Yvan HOUBAERT \\ Ghent University, Department of Metallurgy and Materials Science, Technologiepark 9, B-9052, Ghent, Belgium. \\ E-mail: Roumen.Petrov@rug.ac.be
}

(Received on February 5, 2001; accepted in final form on April 11, 2001)

\begin{abstract}
A TRIP-assisted steel, with a conventional composition containing $0.11 \%$ C, $1.53 \% \mathrm{Mn}$ and $1.26 \% \mathrm{Si}$, and a hot band microstructure composed of ferrite, martensite and carbide particles, was cold rolled with a reduction of $70 \%$. Partially recrystallized samples were obtained by water quenching the cold rolled sheets which were reheated at a constant rate of $10^{\circ} \mathrm{C} / \mathrm{s}$ to temperatures in the range between $525^{\circ} \mathrm{C}\left(<\mathrm{A}_{\mathrm{c} 1}\right)$ and $800^{\circ} \mathrm{C}\left(>\mathrm{A}_{\mathrm{c} 3}\right)$. It was demonstrated that the recovery and recrystallization behaviour was critically controlled by the carbide formation and growth during the initial stages of the annealing treatment. No interaction was observed between recrystallization and transformation phenomena as the static recrystallization was already completely finished before the start of the $\alpha \rightarrow \gamma$ phase transformation. The microtexture observations obtained by orientation imaging microscopy have revealed that the $\langle 111\rangle / / N D$ fibre which dominates the annealing texture at the end of the static recrystallization already starts to develop at the initial nucleation stage. The $\{111\}\langle 110\rangle$ fibre component which is slightly favoured in the recrystallization texture together with other less common BCC annealing components quickly disappear from the ferrite texture after the start of the phase transformation, which could be related to the preferential presence of redissolving carbide particles in these components.
\end{abstract}

KEY WORDS: TRIP assisted steels; recrystallization; carbides; textures; phase transformation.

\section{Introduction}

TRIP assisted steels are characterized by an excellent combination of high strength $(\sim 600-800 \mathrm{MPa})$ and high ductility (elongation at fracture $\varepsilon \sim 25-30 \%$ ). ${ }^{1-5)}$ Cold rolled TRIP steels obtain their final functional properties after a specific two-stage annealing treatment consisting of an intercritical annealing stage between the $A_{1}$ and $A_{3}$ temperatures, followed by an isothermal treatment in the bainitic region. This thermal cycle produces a multi-phase structure in the final product, consisting of equilibrium ferrite, bainitic ferrite and retained austenite islands. Under strain, the retained austenite transforms to martensite producing the TRIP effect, ${ }^{6}$ and in this way the steel obtains an excellent combination of high strength and good ductility. An attractive but not well known advantage of TRIP assisted steels is their low planar anisotropy. In spite of their small $r$-values $(\sim 1)$ TRIP steels display reasonable deep drawing properties ${ }^{5)}$ and the experimental results show that the Erichsen cups are free of ears after drawing. ${ }^{5,7)}$ The reason is the significant effect on the deformation as a consequence of the $\gamma-\alpha^{\prime}$ phase transformation, which starts in the differently stressed and strained micro-regions and thus compensates for the crystallographic anisotropy of the material. Therefore, the functional properties of these steels are determined by the ferrite matrix (ductility), the volume fraction of the retained austenite and by its transformational stability during the deformation, offering both strength and ductility. From this point of view, it is of prime importance to have a detailed understanding of the origin, distribution and crystallographic orientation of the austenitic regions, formed during the intercritical annealing stage of cold rolled TRIP steels. The question whether the $\gamma$ phase during intercritical annealing originates from martensite, strain hardened or recrystallized ferrite still remains unsolved. Also, the precise orientation relationship between austenite islands and the surrounding ferrite matrix still needs further clarification. A precise answer to these questions could open up possibilities for an additional improvement of the ductility and particularly the deep drawability. This would be possible by an appropriate control of the recrystallization process during the intercritical annealing treatment of the cold rolled material.

A further incentive for a better understanding of the recrystallization processes in TRIP steels results from the fast development of new thermomechanical strategies for their production in order to create materials with a better hot dip galvanisability (Al and Si free TRIP steels). The proposed thermomechanical cycle includes quenching after hot rolling followed by a soft annealing and cold rolling. ${ }^{8)}$ During the subsequent intercritical annealing, which is applied to the cold deformed material, with an initial structure of ferrite and carbides, the possible interaction between the recrystallization and $\alpha-\gamma$ phase transformation should not be excluded.

There is a relatively good understanding of the develop- 
Table 1. Composition of the TRIP steel. (mass\%)

\begin{tabular}{|c||c||c||c||c||c||c|c||c||c||c||c||c|}
\hline $\boldsymbol{C}$ & $\boldsymbol{S i}$ & $\boldsymbol{M n}$ & $\boldsymbol{P}$ & $\boldsymbol{S}$ & $\boldsymbol{A l}$ & $\boldsymbol{T i}$ & $\boldsymbol{N}$ & $\boldsymbol{C r}$ & $\boldsymbol{N i}$ & $\boldsymbol{C u}$ & $\boldsymbol{N b}$ & $\boldsymbol{B}$ \\
\hline \hline 0.11 & 1.26 & 1.53 & 0.013 & 0.007 & 0.029 & 0.008 & 0.002 & 0.021 & 0.022 & 0.008 & 0.001 & 0.0005 \\
\hline
\end{tabular}

Table 2. Parameters of the annealing treatment.

\begin{tabular}{|c|c|c|c|c|c||c|c|c|c|c|c|c|c|c|c||c|c|c||c||c||}
\hline № & 1 & 2 & 3 & 4 & 5 & 6 & 7 & 8 & 9 & 10 & 11 & 12 & 13 & 14 & 15 & 16 & 17 & 18 & 19 & 20 \\
\hline \hline $\begin{array}{c}\text { Quench } \\
\text { temperature } \\
\mathrm{T}_{\mathrm{q}},\left({ }^{\circ} \mathrm{C}\right)\end{array}$ & 536 & 557 & 589 & 602 & 629 & 654 & 680 & 701 & 730 & 745 & 754 & 780 & 805 & 797 & 795 & 800 & 800 & 800 & 800 & 800 \\
\hline $\begin{array}{c}\text { Time at } \\
\text { temperature, } \\
\mathrm{S}\end{array}$ & $<1$ & $<1$ & $<1$ & $<1$ & $<1$ & $<1$ & $<1$ & $<1$ & $<1$ & $<1$ & $<1$ & $<1$ & $<1$ & 3 & 9 & 30 & 60 & 180 & 240 & 600 \\
\hline
\end{tabular}

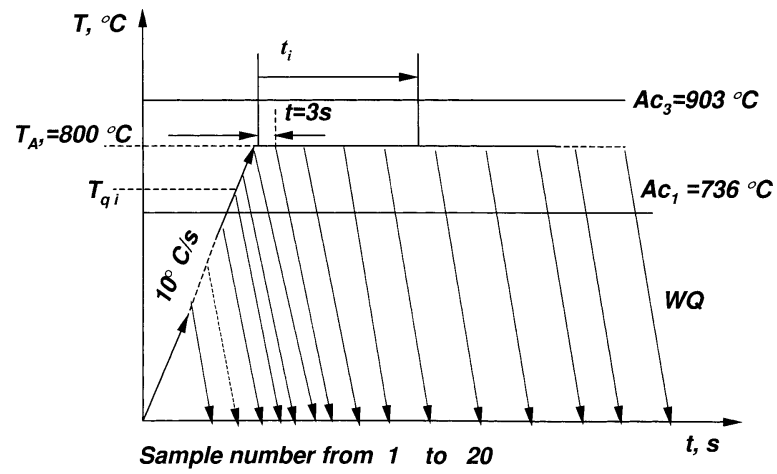

Fig. 1. Scheme of the heat treatment applied to $70 \%$ cold rolled samples. The precise values of temperatures $T_{\mathrm{qi}}$ and soaking times $t_{\mathrm{i}}$ are mentioned in Table 1 .

ment of the $\{111\}$ deep drawing texture in single phase, ferrite low carbon steels. Very little has been published, however, on the textures of multi-phase steels obtained after cold rolling and annealing. ${ }^{9,10)}$ For these steels the final texture is not only the result of cold rolling and recrystallization, but also the phase transformation may play a significant role. For the conventional deep drawing steels it is widely accepted that the favorable $\{111\}$ fibre texture is generated by a high stored energy nucleation mechanism, because $\{111\}$ deformed grains have the high stored energy of plastic deformation. ${ }^{11)}$ In multiphase steels though, various obstacles can hamper the nucleation of $\{111\}$ orientations: e.g. the presence of $\mathrm{C}$-interstitials, which will interfere with the subgrain coarsening, or the presence of second phase particles, which will generate local deviations from the plane strain deformation mode.

In order to investigate the problems mentioned above, the recrystallization behavior of a $70 \%$ cold rolled TRIP steel was studied during the reheating stage of a typical intercritical annealing treatment.

\section{Experimental}

A hot rolled steel sheet ( $3.5 \mathrm{~mm}$ thickness) with a chemical composition shown in Table $\mathbf{1}$ and an initial structure consisting of ferrite, tempered martensite and carbides was cold rolled with a reduction of $70 \%$. The value of the critical temperatures $\left(A_{c 1}=736^{\circ} \mathrm{C}\right.$ and $\left.A_{c 3}=903^{\circ} \mathrm{C}\right)$ was determined by dilatometry tests on the hot rolled specimen.

Specimens of size $80 \times 15 \times 1 \mathrm{~mm}$ were cut from the cold

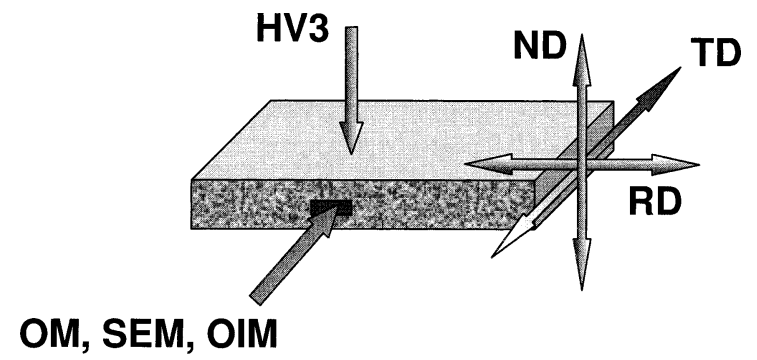

Fig. 2. Scheme of the planes sectioned for mechanical and microstructural observation.

rolled sheet parallel to the rolling direction (RD) and were annealed according to the cycle of Fig. 1 in an infrared furnace. A heating rate of $10^{\circ} \mathrm{C} / \mathrm{s}$ was applied in this experiment and the values of the temperatures and isothermal soaking times are presented in Table 2. All specimens were subsequently water quenched after heating or isothermal soaking.

The recrystallization processes were studied by monitoring the changes in mechanical properties (hardness HV3) and in microstructural evolution, which was evaluated by Light Optical Microscopy (LOM), Scanning Electron Microscopy (SEM) and micro texture analysis. The latter was carried out by employing an Orientation Imaging Microscopy (OIM) attachment installed on a Philips XL30 ESEM microscope with an LaB6 filament. The specimens for optical metallography and SEM were prepared according to the classical procedure (mechanical grinding and polishing up to a $1 \mu \mathrm{m}$ diamond paste) followed by $2 \%$ nital or Le Pera etching, after additional sub-micron polishing. The carbide size was measured in at least 10 different fields of each sample by means of the SEM at a magnification of more than $10^{4}$ and the results were averaged. The Vickers hardness (HV3) was measured in the rolling plane (Fig. 2) after grinding followed by $3 \mu \mathrm{m}$ diamond paste polishing, and the results are obtained as an average value from at least 10 measurements. The OIM scans were collected in a plane perpendicular to the transverse direction (TD) (Fig. 2) after electrolytic polishing and 2\% nital etching. The electron backscattering diffraction (EBSD) patterns were acquired and analyzed by means of the $\mathrm{TSL}^{\circledR}$ software. The OIM data were further post-processed with the texture software developed by Van Houte. ${ }^{12)}$ 


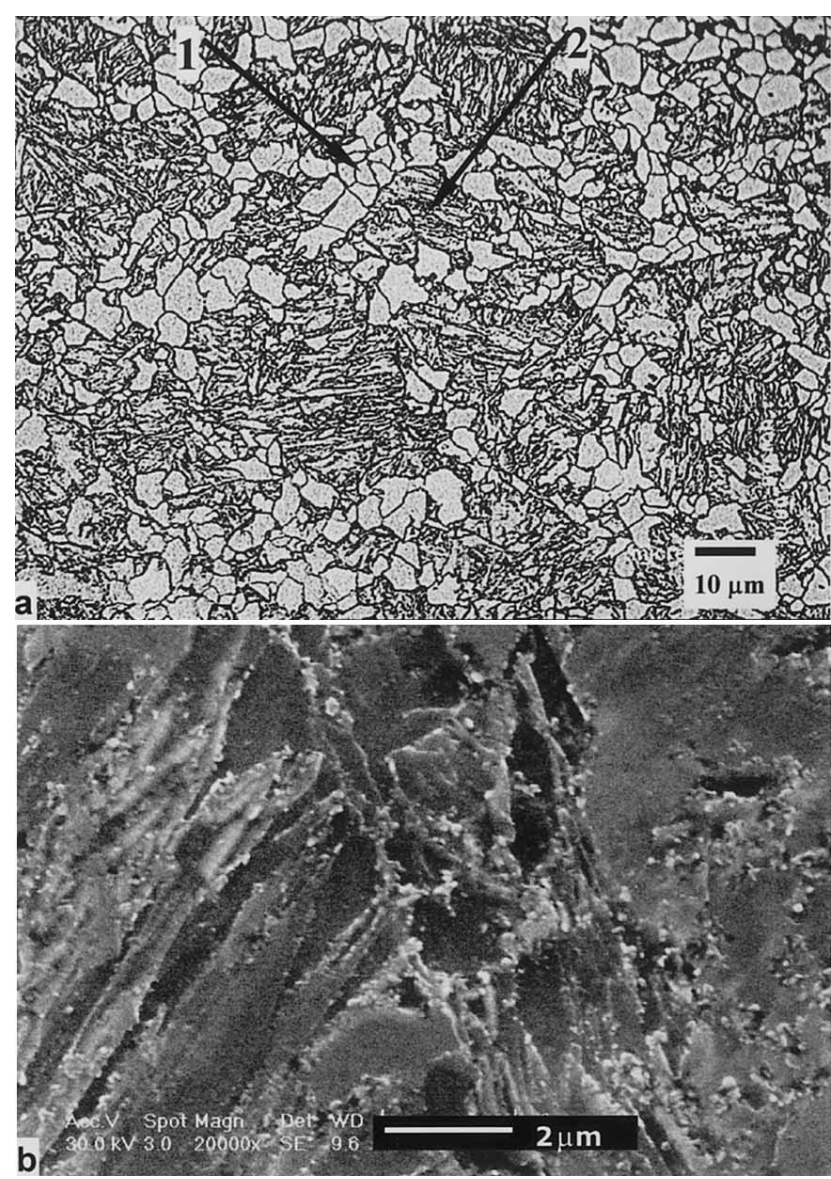

Fig. 3. Microstructure of the hot rolled material with (a) exhibiting the ferrite (1) and the martensite (2) phases, and (b) showing small carbide particles in the martensite plates.

\section{Results}

\subsection{Hardness and Microstructure}

The microstructure of the initial material is shown in Figs. 3(a) and 3(b). The hot band microstructure consists of three phases: (i) small ferritic grains, emerging from hot rolled and recrystallized austenite (allotriomorphic ferrite); (ii) partially tempered martensite, which was obtained during a 10 min tempering treatment at $500^{\circ} \mathrm{C}$; and (iii) small carbides, which have precipitated from the martensite.

The micrographs and the hardness data were used to study the recovery and recrystallization behavior of the material during the reheating. Five different regions are clearly visible in the evolution of the hardness HV3 as a function of the quenching temperature (Fig. 4). From these data the start temperature of primary recrystallization was determined to be $670^{\circ} \mathrm{C}$, and correspondingly the first recrystallization nuclei could be observed in the microstructure after quenching from $680^{\circ} \mathrm{C}$, producing a recrystallized volume fraction of $\sim 7 \%$.

The size of the recrystallization nuclei at this temperature is still small $(<2 \mu \mathrm{m})$ but in some regions abnormally large isolated nuclei of $\sim 5 \mu \mathrm{m}$ were observed. The first recrystallization nuclei are situated mainly at the ferritemartensite interface but the nuclei have grown only into the (hard) martensite band (Figs. 5(a) and 5(b)). Whether these nuclei originate from the martensite or the ferrite side of the interface could not be established in the present obser-

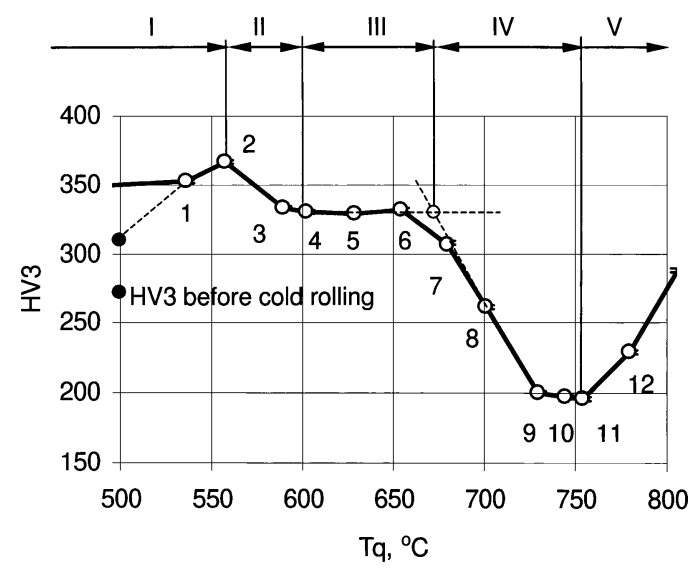

Fig. 4. Hardness HV3 as a function of the quench temperature.

vations. Figures. 5(c) and 5(d) show that a cellular structure is present in the deformed martensite regions with small carbide particles at the cell walls.

The orientation of the recrystallization nuclei was determined by means of OIM. It also allows to determine the recrystallized volume fraction by employing the Image Quality factor (IQ) of the EBSD pattern, which quantifies the band contrast of the Kikuchi lines. In general, the deformed matrix material has a much lower IQ factor than the emerging recrystallization nuclei. Based on these data, Fig. 6 shows the amount of recrystallized volume fraction as a function of quench temperature. In the same way the martensite phase fraction, which first appears in the microstructure after water quenching from $754^{\circ} \mathrm{C}$ was quantified (specimen \#11, Table 2) as also the martensite phase can be distinguished by inferior IQ values as compared to the surrounding ferrite regions.

Figure 6 also shows the changes in the carbide size during the heating as a function of temperature. The average carbide size increases from $116 \mathrm{~nm}$ in the initial material up to $325 \mathrm{~nm}$ in the specimen quenched from $754^{\circ} \mathrm{C}$, when the first martensite regions were observed in the microstructure. In the initial stage of reheating, at temperatures between 525 and $650^{\circ} \mathrm{C}$ the average carbides size increases to $\sim 180 \mathrm{~nm}$; the carbides have almost a spherical shape and they are still uniformly distributed in the microstructure. Increasing the temperature first leads to carbide precipitation on the grain boundaries or cell walls and next, after the end of primary recrystallization, to the formation of big carbide conglomerates, some of them clustered at the grain boundaries.

\subsection{Texture Data}

Figure 7 shows the $\varphi_{2}=45 \mathrm{deg}$ sections of the ferrite ODFs measured after subsequent processing steps. These texture maps can be analysed on the basis of the key presented in Fig. 7(a). The hot band texture of Fig. 7(b) displays the typical transformation components obtained from a cube parent orientation which is the characteristic component of the recrystallized austenite phase. After cold rolling the conventional RD-ND fibre texture arises with $\langle 110\rangle / /$ $\mathrm{RD}$ and $\langle 111\rangle / / \mathrm{ND}$, respectively, (cf. Fig. 7(c)). The early nucleation texture observed after a recrystallized volume fraction of $9 \%$ (cf. Fig. 7(d)) displays an ND fibre texture together with a component on the cube fibre and the Goss 


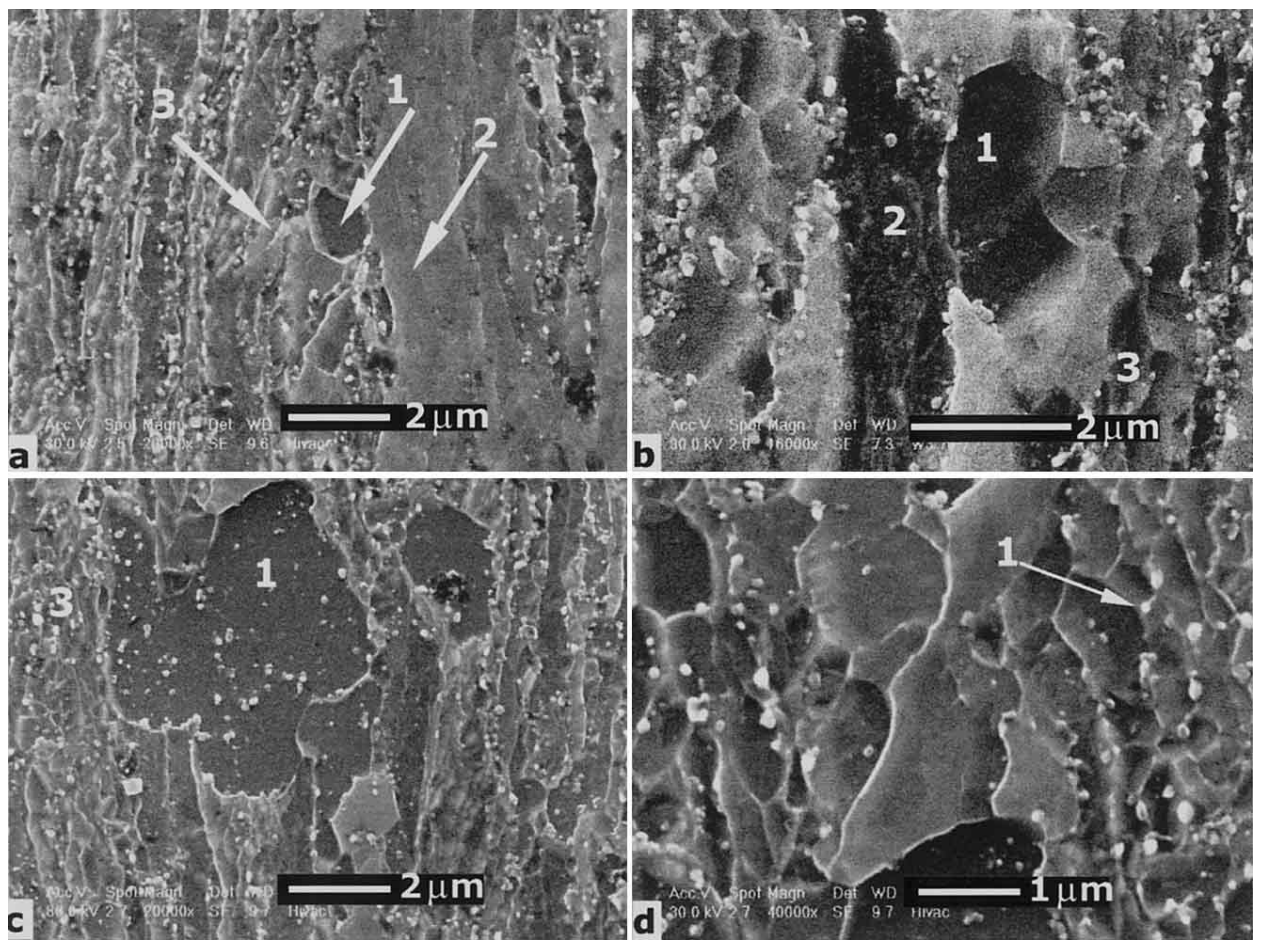

Fig. 5. Microstructures observed at the initial stages of recrystallization; (a) and (b) isolated recrystallization nuclei (1) at the ferrite (2)-martensite (3) interface, observed in samples with quench temperature $T_{\mathrm{q}}=680^{\circ} \mathrm{C}$; (c) nucleus (1) growing into the surrounding tempered martensite matrix (3), which is characterised by a cellular structure; (d) detail from the cellular structure exhibiting particles (1) preferentially on the cell walls. For both (c) and (d) $T_{\mathrm{q}}=701^{\circ} \mathrm{C}$.

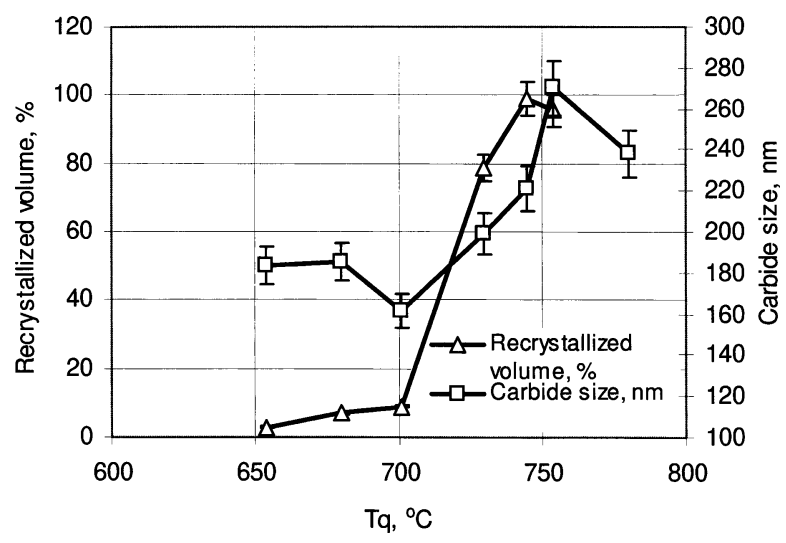

Fig. 6. Recrystallized volume fraction and carbide size vs. quench temperature.

orientation $(\{110\}\langle 001\rangle)$. Although the intensity distribution along the ND fibre is fairly homogeneous, a significant maximum appears on the $\{111\}\langle 110\rangle$ component at the expense of the $\{111\}\langle 211\rangle$ component.

At the end of the recrystallization, but before the onset of the $\alpha \rightarrow \gamma$ phase transformation, a relatively weak ND fibre is observed (cf. Fig. 7(e)) with a large spread around the fibre skeleton and some residual intensity on the RD fibre as well as in other less typical regions of the Euler space. The slight preference of the $\{111\}\langle 110\rangle$ component has persisted throughout the growth stage of recrystallization. After the start of the $\alpha \rightarrow \gamma$ phase transformation $(\sim 14 \%$ of transformed volume fraction) this $\{111\}\langle 110\rangle$ component has largely disappeared from the remaining ferrite texture, and thus an ND fibre is observed with a marked maximum on the $\{111\}\langle 211\rangle$ component (cf. Fig. 7(f)). Also the resid- ual intensity on the RD fibre and the atypical annealing components have almost completely vanished right after the start of the transformation.

\section{Discussion}

\subsection{The Deformed Structure}

The initial microstructure of the material determines its behavior during the cold deformation and the subsequent recrystallization, and therefore, it is of great importance for understanding the recrystallization mechanism.

The behaviour of the steel during the cold deformation will be very complicated, because of the mixed initial structure in which the various components have different mechanical properties. The soft ferrite is surrounded by the harder martensite phase, which contains even harder, small carbide particles. It is reasonable to assume that after cold rolling the strain distribution in the steel is quite heterogeneous from a microstructural point of view. The soft ferrite matrix will be subjected to the largest strain whereas the hard martensitic phase will accumulate the least deformation energy and an average level of deformation will be observed in the ferrite zones enclosed between the martensitic plates. Such a highly heterogeneous distribution of strain requires the existence of plastic accommodation strains at the phase boundaries, which therefore will become potential nucleation sites for recrystallization.

Furthermore, it is noted that the carbon content in the deformed allotriomorphic ferrite is less than in the martensite, which was not completely tempered. Therefore, the carbon from the martensite phase will continue to precipitate during the heating and it might affect both the recovery and the 

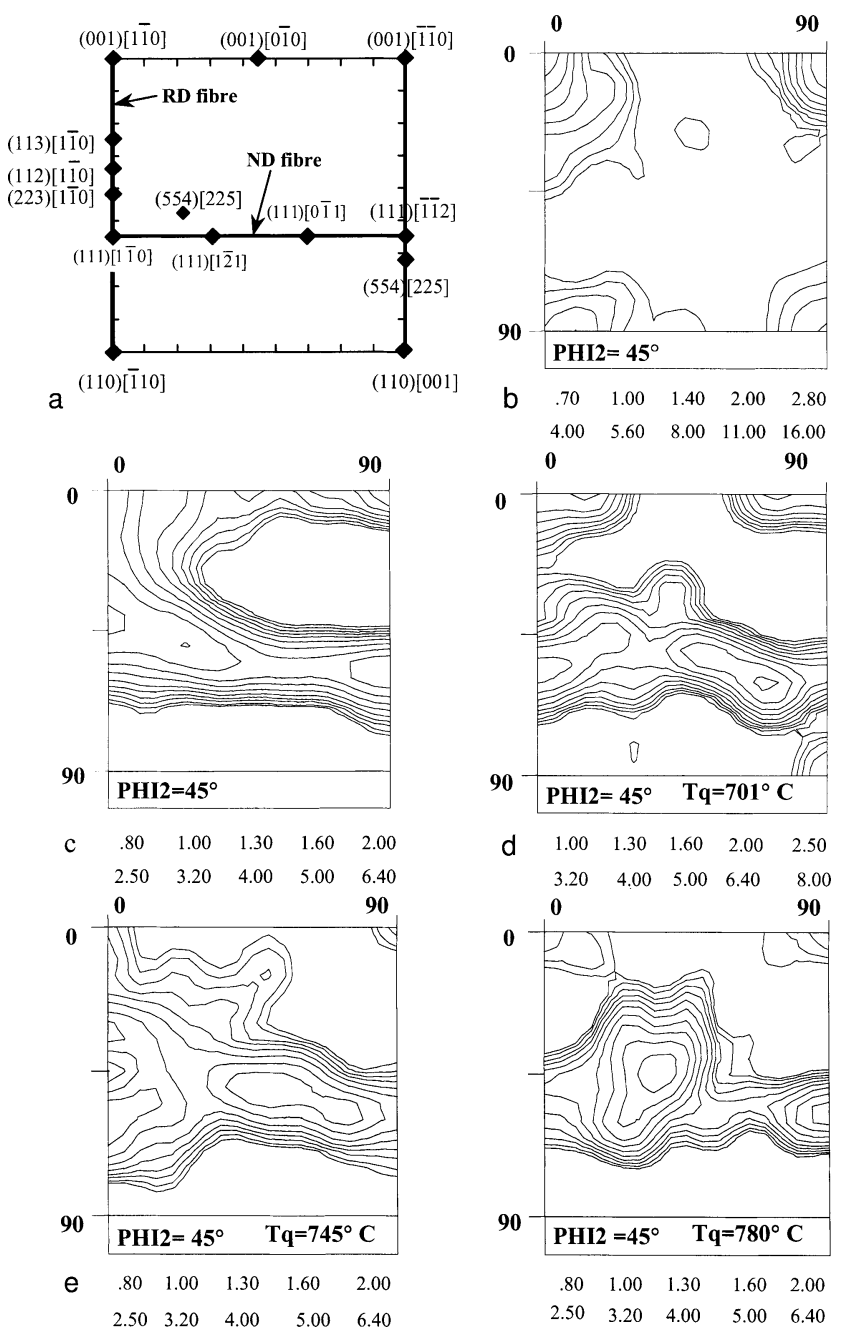

Fig. 7. $\varphi_{2}=45^{\circ}$ sections of ODFs of the subsequent stages of the thermo-mechanical processing procedure. (a) Key with representative $\mathrm{BCC}$ rolling and annealing components; (b) hot band texture; (c) 70\% cold rolled texture; (d) ODF of recrystallization nuclei after $9 \%$ of recrystallized volume fraction); (e) $100 \%$ of recrystallized volume fraction, but before the start of the phase transformation; (f) residual ferrite texture after formation of $14 \%$ volume fraction of martensite.

recrystallization processes. Given the very small size of the carbide particles during cold rolling $(<100 \mathrm{~nm})$ it is unlikely that they will have affected the local strain mode. ${ }^{13)}$ But as their size and density change significantly during the heating, their effect on the recovery or even the recrystallization should not be excluded.

\subsection{Changes in Hardness and Microstructure during Reheating}

It is possible to determine five different regions in the Hardness $v s$. Temperature curve of Fig. 4. In the first stage (stage I) the hardness increases with $\sim 16 \%$. It is assumed that the observed hardening is a consequence of strain aging of the material - the dislocations are pinned by carbon atoms and small carbide precipitates, which cannot be observed by SEM. The process starts at low temperatures (at $\sim 200^{\circ} \mathrm{C}$ ) and develops fast because of the very high diffusivity of the carbon atoms. This assumption was experimentally confirmed by isothermal aging of the cold rolled specimens at $200^{\circ} \mathrm{C}$ for different times and the results are

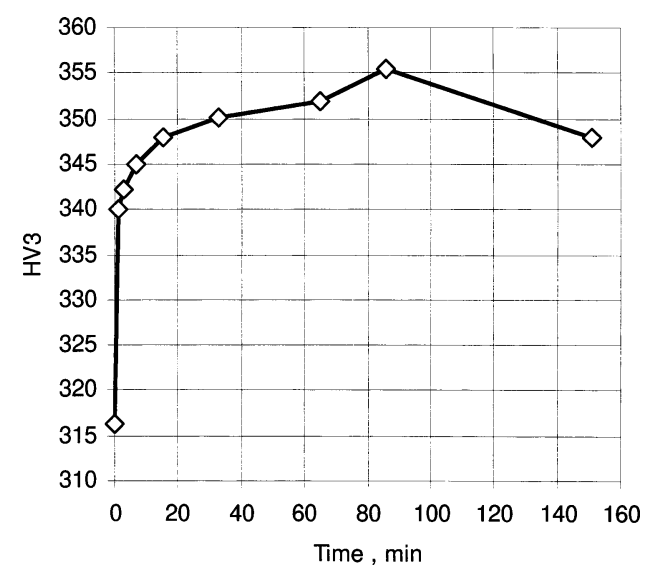

Fig. 8. Hardness $\mathrm{HV} 3$ vs. annealing time at $200^{\circ} \mathrm{C}$.

presented in Fig. 8. The same hardness of 365 HV3 was reached in the specimens after $90 \mathrm{~min}$ tempering at $200^{\circ} \mathrm{C}$, and after heating up to $557^{\circ} \mathrm{C}$ with a heating rate of $10^{\circ} \mathrm{C} / \mathrm{s}$ and water cooling.

The coarsening of the small carbides at elevated temperature might be a reason for the disappearance of their pinning effect. As a result, the hardness in the second stage (stage II, Fig. 4) decreases down to the initial value after cold rolling, which triggers the onset of the recovery process, characterized by reconfiguration and annihilation of dislocations. Before the actual start of static recrystallization, there is a third stage (stage III, Fig. 4) during which the hardness remains constant, and which features the transition from the recovery to the recrystallization stage. It is believed that in the transition stage, the recovery process develops simultaneously with carbide precipitation and growth. The precipitated carbon originates from the martensite phase, which still contains a high content of carbon in the supersaturated solid solution and with the increase of the temperature the equilibrium condition is gradually restored. The concurrent precipitation and growth of carbides produces a stage of stable hardness.

In the present conditions of continuous heating the primary recrystallization overlaps with the recovery stage. The microstructural observation showed the coexistence of a cellular structure (honeycomb type) and isolated recrystallization nuclei up to $700^{\circ} \mathrm{C}$. A number of small carbides were observed at the cell walls, (Figs. 5(c) and 5(d)) showing that they probably retard the recrystallization by suppressing the mobility of subgrain boundaries.

As it was already mentioned above, the recrystallization start temperature of $670^{\circ} \mathrm{C}$ was determined from the hardness data (Fig. 4) and this temperature corresponds very well to the microstructural observations of Figs. 5(a) and 5(b), where the first small isolated nuclei with a size of 1 to $1.5 \mu \mathrm{m}$ are clearly observed. They are situated preferably at the martensite-ferrite interface and only consume the surrounding martensite, but it is impossible to ascertain at which side of the boundary they nucleated. No carbides are present in these nuclei as compared to the observed recrystallized grains in the later stages of recrystallization, and thus it can be derived that they probably appear in the relatively poor carbide regions. Although it is readily understood that the martensite-ferrite phase boundaries act as potent nucleation sites, in view of the local compatibility 

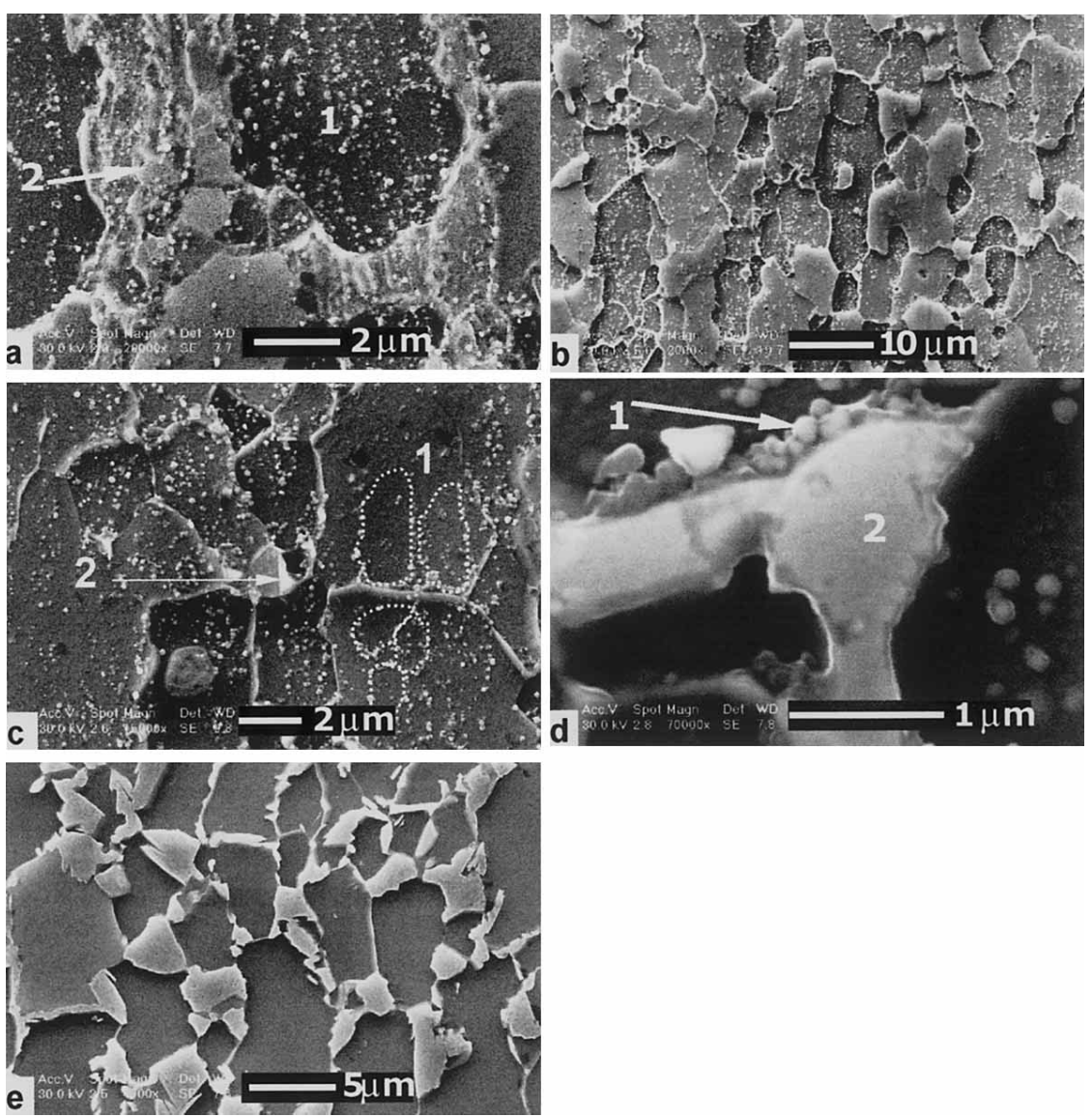

Fig. 9. Microstructural evolution during the recrystallization; (a) recrystallizing ferrite grains (1) consuming the cellular structure of the deformed matrix $(2)\left(T_{\mathrm{q}}=730^{\circ} \mathrm{C}\right)$; (b) fully recrystallized microstructure consisting of ferrite and carbides, before the onset of the phase transformation $\left(T_{\mathrm{q}}=745^{\circ} \mathrm{C}\right)$; (c) the carbides are precipitated along former cell walls (1) and the first martensite (2) appears in the microstructure $\left(T_{\mathrm{q}}=754^{\circ} \mathrm{C}\right)$; (d) not yet dissolved carbides (1) remaining near the martensite (2) $\left(T_{\mathrm{q}}=780^{\circ} \mathrm{C}\right)$; (e) initial stage of isothermal soaking $\left(T_{\mathrm{q}}=805^{\circ} \mathrm{C}\right)$ displaying $18 \%$ martensite fraction and complete carbide dissolution.

strains, it is far more difficult to explain why the newly recrystallized grains only consume the martensite. A possible reason for this behavior is the assumed high dislocation density in the martensite grains as compared to the ferrite regions. The martensite accumulates dislocations both from the martensitic transformation mechanism and additional strain hardening during cold rolling.

A fast decrease of the hardness was observed in the temperature range from 670 to $725^{\circ} \mathrm{C}$ (Fig. 4, stage IV). The cellular structure almost completely disappears after increasing the quenching temperature to $725^{\circ} \mathrm{C}$, when the recrystallized volume fraction is $80 \%$ according to the microstructural observations and the OIM scan data. At this temperature, the ferritic grains are completely recrystallized, but still slightly elongated along the rolling direction. Small regions with a cellular-like structure persisted between some of the ferritic grains (Fig. 9(a)). These regions finally disappear after increasing the temperature up to $745^{\circ} \mathrm{C}$ when the recrystallization is completely finished (Fig. 9(b)). At the end of primary recrystallization the microstructure consists only of slightly elongated ferritic grains, small carbides (140-200 nm), mainly situated inside the ferritic grains and larger carbide particles $(250-500 \mathrm{~nm})$ mainly clustered in conglomerates near the grain boundaries. Although the quench temperature of $745^{\circ} \mathrm{C}$ is higher than the $\mathrm{A}_{\mathrm{cl}}$ temperature $\left(736^{\circ} \mathrm{C}\right)$ for the steel, a measurable quantity of martensite could not be detected in the microstructure (Fig. 9(b)).

Figure 9(c) shows that after increasing the temperature to $754^{\circ} \mathrm{C}$ the austenite formation starts which produces a quenched microstructure with an approximately volume fraction of $2-3 \%$ martensite, situated at the ferrite grain boundaries. A further increase of the temperature leads to a gradual progress of $\alpha-\gamma$ phase transformation and produces a fast increase of the hardness after quenching (Fig. 4, Stage V). Small carbides still exist in the ferritic grains, but they do not act as nucleation precursors for austenite formation. Figures 9(c) and 9(d) show a martensitic regions with still non-dissolved carbide particles in the vicinity, respectively in specimens quenched from $754^{\circ} \mathrm{C}$ and $780^{\circ} \mathrm{C}$. The carbide dissolution is completely finished at $805^{\circ} \mathrm{C}$ (Fig. 9(e)) and approximately $18 \%$ martensite phase is present in the microstructure.

In view of the above observation, one can conclude that there is no direct interaction between recrystallization and phase transformation during the annealing treatment. The first measurable fraction of the martensite phase was only observed after the completion of the recrystallization. In the present material it is the formation, growth and dissolution of carbide particles, which control both the recrystallization and transformation phenomena. They are also responsible for suppressing the nucleation of a large amount of nuclei 
as observed in mild steels and for preserving the cellular structure in the deformed martensite until the latest stages of recrystallization.

\subsection{Changes in the Texture}

As a first approximation, the development of the recrystallization texture in this complex multi-phase structure is similar to the formation of annealing textures in the single phase extra-low carbon steels. The nucleation stage of the recrystallization process is strongly dominated by ND fibre orientations which are identified as high stored energy components, ${ }^{13)}$ i.e. orientations with the highest plastic power dissipation and therefore with the highest driving force for nucleation. Likewise to low carbon mild steels the characteristic curvature of the ND fibre with respect to the fibre skeleton is also present from the early stages of nucleation indicating that similar nucleation mechanisms are operating as the ones that are reported in literature. ${ }^{14)}$ In addition to ND fibre components there are also nuclei orientations on the cube fibre and near the Goss component. The former are generally associated with the bulging mechanism of recrystallization $^{15)}$ whereas the latter are typical for shear band nucleation. ${ }^{16)}$

The final recrystallization texture is completely dominated by the ND fibre, which displays a maximum on the $\{111\}\langle 110\rangle$ component. Although there still is some residual intensity along the RD fibre, in the range $0<\Phi<30 \mathrm{deg}$, and in other less common regions of Euler space, the maximum on the cube fibre and the Goss component have disappeared showing that these orientations were consumed during the growth stage of recrystallization. Probably this is not caused by a simple size disadvantage (i.e. a growth disadvantage due to a smaller grain size) because Fig. 7(d) shows that these orientations were among the first to nucleate. Therefore, it is more likely that an active pinning mechanism has played a role (e.g. particle pinning or orientation pinning).

Figure $7(f)$ shows that the $\{111\}\langle 110\rangle$ grains are among the first to be transformed to the austenite phase, leading to their disappearance from the ferrite matrix right after the start of the phase transformation. Austenite nuclei are preferentially formed at carbon rich sites of the microstructure, such as in the vicinity of redissolving carbide particles which are mainly located at pre-existing grain boundaries of the cold rolled structure. The present data thus imply that $\{111\}\langle 110\rangle$ orientations contain more carbide particles than $\{111\}\langle 211\rangle$ grains, which can be accounted for by taking into consideration that the former orientations mainly nucleate at the carbide rich grain boundaries between cold rolled ND fibre grains, ${ }^{17)}$ whereas the latter orientations predominantly nucleate near carbide poor in-grain strain heterogeneities, ${ }^{18)}$ as schematically outlined in Fig. 10.

Another recrystallization mechanism that might be of interest in the present context is particle stimulated nucleation (PSN). PSN is often observed in particle containing aluminium alloys and it is said to lead to a randomization of the annealing texture, because of the arbitrary deformation mode in the vicinity of hard inclusions in the plastic matrix. ${ }^{19)}$ The present TRIP steel also contains many carbide particles and a hard martensite phase during cold

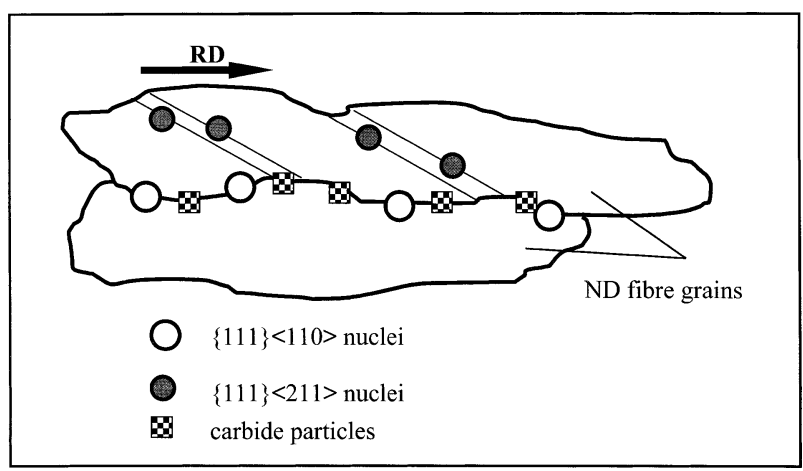

Fig. 10. Schematic representation of the possible nucleation sites of the $\{111\}\langle 110\rangle$ and $\{111\}\langle 211\rangle$ components.

rolling. Although the carbide particles size is probably too small for affecting the local strain mode, the martensite inclusion might have influenced the microscopic strain instead. Therefore, PSN cannot be excluded as a potential recrystallization mechanism. Although the microstructural observations did not give any direct evidence, it is noticed nevertheless that the recrystallization textures are less intense compared to conventional annealing textures of low carbon steels, implying a larger random component for the steel which is presently under investigation. Moreover, in the full recrystallization texture of Fig. 7(e) some irregular components are present which are usually not observed in single-phase low carbon steels. Because these components are also among the first disappearing ones at the onset of the phase transformation, they are presumably formed in carbon rich regions of the microstructure, e.g. in the vicinity of carbide particles, which are preferentially present in the former martensite regions. Therefore, it might be an indication that PSN has played a role in the formation of the annealing texture.

\section{Conclusions}

For the studied $70 \%$ cold rolled TRIP assisted steel with a hot band microstructure containing ferrite, tempered martensite and carbides, it was found that the recrystallization was finished before the start of the $\alpha \rightarrow \gamma$ phase transformation, under the investigated condition of a constant reheating rate of $10^{\circ} \mathrm{C} / \mathrm{s}$. The recovery and recrystallization phenomena were largely controlled by the kinetics of carbide precipitation and growth. The onset of static recrystallization coincides with the critical increase of carbide particle size, producing a local unpinning of the subgrain boundaries and leading to a small number of large, isolated recrystallization nuclei. These nuclei were mainly located at the ferrite-martensite interface because these sites provide the potential of an increased driving force due to a higher stored energy (associated with the local strain incompatibilities) and an increased ability for carbide precipitation and growth which are both essential prerequisites for the nucleation process.

Likewise to the well-known extra-low carbon steels, the recrystallization produced the characteristic ND fibre texture with a slight maximum on the $\{111\}\langle 110\rangle$ component. In addition to this ND fibre also less common components are present in the annealing texture. The $\{111\}\langle 110\rangle$ orien- 
tations together with the non-typical components preferentially disappear from the ferrite texture right after the start of the $\alpha \rightarrow \gamma$ phase transformation. This selective transformation phenomenon was attributed to the preferred presence of redissolving carbide particles in the transforming orientations.

\section{Acknowledgments}

The authors gratefully acknowledge the financial support from the Belgian State: Prime Minister's Office: Federal Office for Scientific, Technical and Cultural Affairs (Interuniversity Poles of Attraction Program, under contract P4/33).

\section{REFERENCES}

1) A. Itami, M. Takahashi and K. Ushioda: Symp. Proc. HSS for Automotive, C.A. Slater, Warrendale, PA, (1994), 246.

2) K. Sugimoto and M. Kobayashi: Symp. Proc. HSS for Automotive, C.A. Slater, Warrendale, PA, (1994), 258.

3) A. Di Chiro, J. Root and S. Yue: 37MWSP Conf. Proc., ISS, Warrendale, PA, (1996), 373.

4) M. De Meyer, D. Vanderschueren and B. C. De Cooman: ISIJ Int.,
39 (1999), 813.

5) T. Heler, B. Engl, B. Ehrhardt and J. Esdohr: 40MWSP Conf. Proc., ISS, Warrendale, PA, (1998), 25.

6) V. F. Zackay, E. R. Parker, D. Fahr and R. Bush: Trans. Am. Soc. Met., 60 (1967), 252.

7) E. Girault: Ph. D. Thesis, MTM, KULeuven, (1999).

8) K. Eberle, P. Cantineaux and Ph. Harlet: Ironmaking Steelmaking, 26, (1999), No. 3, 176.

9) I. Samajdar, E. Girault, B. Verlinden, E. Aernoudt and J. van Humbeeck: ISIJ Int., 38 (1998), No. 9, 998.

10) D. K. Mondal and R. K. Ray: Recrystallization ' 90 , ed. by $T$. Chandra, TMS, Warrendale, PA, (1990), 795.

11) I. L. Dillamore, C. J. E. Smith and T. W. Watson: Metal Science J., 1 (1967), 49.

12) P. Van Houte: User manual, MTM-FHM Software, Ver., 2 ed. by MTM-KULeuven, (1995).

13) F. J. Humpreys and M. Hatherly: Recrystallization and Related Annealing Phenomena, Elsevier Science Ltd., Oxford, (1995), 266.

14) R. H. Goodenow: Trans. Am. Soc. Met., 59 (1966), 804.

15) F. J. Humphreys and M. Hatherly: Recrystallization and Related Annealing Phenomena, Elsevier Science Ltd., Oxford, (1995), 207.

16) K. Ushioda and W. B. Hutchinson: ISIJ Int., 29 (1989), 862.

17) H. Inagaki: ISIJ Int., 34 (1994), 313.

18) M. R. Barnett: ISIJ Int., 38 (1998), 78.

19) F. J. Humphreys, Acta Metall., 25 (1977), 1323. 